\title{
CARDIOVASCULAR RISK FACTORS AND METABOLIC SYNDROME IN A POPULATION OF YOUNG STUDENTS FROM THE NATIONAL UNIVERSITY OF COLOMBIA
}

\author{
John Edwin Feliciano-Alfonso ${ }^{1 *}$, Carlos Olimpo Mendivil², Iván Darío Sierra Ariza ${ }^{3}$, Clara Eugenia Pérez ${ }^{4}$
}

Study conducted at the División de Lípidos y Diabetes, Departamento de Ciências Fisiológicas, Facultad de Medicina, Universidad Nacional de Colombia, Bogotá, Colombia

\author{
*Correspondência: \\ Laboratorio 418. División \\ de Lípidos y Diabetes \\ Facultad de Medicina \\ - Edificio 471, Ciudad \\ Universitaria \\ Carrera 30 No 45-03. \\ Universidad Nacional de \\ Colombia, Bogotá D.C., \\ Colombia \\ Tel: 3165000, Ext: 15054; \\ 3165479 \\ jefelicianoa@yahoo.com
}

\begin{abstract}
SUMMARY
Овлестіve. To estimate prevalence and distribution of cardiovascular risk factors and Metabolic Syndrome (MS) in young individuals admitted to the National University of Colombia in Bogotá.

Methods. An analytic cross-sectional study was conducted in a sample of 249 individuals of both genders aged 15 to 20 years. A questionnaire was personally administered to collect demographic, socioeconomic, smoking, perinatal, and women's health data. Anthropometric measurements, blood pressure, and a fasting blood sample were taken. Prevalence of MS was determined and compared using criteria from several qualified institutions.

Results. We found a high prevalence of smoking (18.9\%), arterial prehypertension (14.1\%) and overweight (11.2\%), 9.2\% of study participants had prediabetes, and the most frequent dyslipidemia was low HDL cholesterol (13.3\%). Alcoholic beverage consumption was declared by $60.6 \%$ of study participants. Body mass index was associated with significant increases in blood pressure, LDL cholesterol and plasma triglyceride levels. Gestational age at birth was inversely associated with presence of low HDL cholesterol levels and high blood pressure. Prevalence of the MS varied markedly according to the definition employed: 9.2\% using REGODCI (Research Group on Diabetes and Chronic IIInesses) criteria, 2\% using IDF (International Diabetes Federation) criteria, and 2.4\% using AHA (American Heart Association) criteria.

Conclusion. The encountered prevalence of modifiable cardiovascular risk factors justifies promotion of therapeutic lifestyle changes among this age group in Colombia. Further harmonization of MS criteria in young individuals is needed.
\end{abstract}

KEY wORDS: Risk factors. Adolescent. Metabolic syndrome X obesity. Alcohol consumption.

\section{INTRODUCTION}

Despite well established criteria for diagnosis of cardiovascular risk factors (CVRF) in adults, the same is not true for children and adolescents, in part due to the marked physiological changes that occur in this period ${ }^{1}$. However, puberty alone cannot explain the establishment of CVRF, since there are environmental ${ }^{2}$, socioeconomic and psychological conditions ${ }^{3}$ that influence onset. It has been documented that presence of hypercholesterolemia, smoking and high blood pressure (HBP) between ages 6 and 30 are associated with appearance of atherosclerotic lesions later in life ${ }^{4}$ and the number of CVRF is directly related to the severity of these lesions ${ }^{5}$. The clustering of certain CVRF (obesity, hyperglycemia, hypertriglyceridemia, low levels of high density lipoprotein cholesterol and HBP), sometimes referred to as the "metabolic syndrome" (MS), may foster development of early cardiovascular events; causing losses for society, increasing the cost of health services and negatively affecting patients' quality of life.

In spite of these implications and of the fact that cardiovascular diseases are the main cause of death in Colombia ${ }^{6}$, there is still scarce data about the prevalence of CVRF and almost no documents about prevalence of MS in the young Colombian population.

Therefore, the objective of this study was to estimate the

1. Médico Cirujano Candidato Maestría Epidemiología Clínica Universidad Nacional de Colombia e Docente e Investigador División de Lípidos y Diabetes Facultad de Medicina Universidad Nacional de Colombia, Bogotá, Colombia

2. Médico Cirujano Especialista en Estadistica Universidad Nacional de Colombia; Candidato Doctorado Bioquímica Nutricional Universidad de Harvard e Profesor Universidad de los Andes, Bogotá, Colombia

3. Médico Especialista en Diabetes y Nutrición - Profesor Titular y Director División de Lípidos y Diabetes Presodente Electo Asociación Latinoamericana de Diabetes (ALAD), Bogotá, Colombia

4. Maestría en Bioquímica - Docente e Investigador División de Lípidos y Diabetes, Bogotá, Colombia 
prevalence and distribution of CVRF in youngsters admitted at the National University in Bogotá at the beginning of their first academic year, and to describe prevalence of MS in this population according to the definitions proposed by REGODCl (Research Group on Diabetes and Chronic IIInesses), the AHA (American Heart Association) and IDF (International Diabetes Federation). Since clinical evidence suggests that early life conditions, and in particular gestational age and weight at birth may influence the future development of CVRF (7), our study sample also analyzed the association between these two variables and CVRF.

\section{Methods}

The target population of this study comprised individuals of both genders between 15 and 20 years of age and residents of Bogotá for three months or more admitted to an undergraduate program at the National University of Colombia in Bogotá $\left(73.7 \%\right.$ of all admitted students) ${ }^{8}$ for the second semester of 2005 or the first of 2006.

Students 18 years or older who did not provide informed consent, or those e under 18 whose parents did not sign the consent were excluded.

Sample size was estimated by the formula for cross-sectional studies that seek to estimate a proportion ${ }^{9}: n=\left[P(1-P) / D^{2}\right]$ $F_{(1-a)}$. Where $\alpha$ represents the probability of type I error (5\%), $P$ represents the expected prevalence of $\mathrm{MS}(4.2 \%)^{10}$, and D represents the sampling error $(2.5 \%)$. The formula yielded a sample size of 247 individuals, but was increased so that the sampling error would be $2.5 \%$ even with a no response rate of $20 \%$. Selection was carried out by simple random sampling from the database of all subjects admitted to the University for the II-2005 and I-2006 semesters, provided by the Office of Admissions. Potential participants were contacted by telephone between October 2005 and July 2006, and an appointment was made for the informed consent process. Individuals who provided informed consent were scheduled for interview, physical exam and laboratory tests. The study was approved by the Faculty of Medicine IRB, and all participants provided written informed consent. For participants under 18, the informed consent document was also signed by their legal representative.

\section{Procedures}

During the interview information about family history of disease, personal medications, women's health, perinatal history (weight and gestational age at birth), alcohol consumption and smoking was collected. Height, weight, waist circumference (WC), bioelectrical impedance and blood pressure were measured at physical exam. Body weight and percent body fat were determined using a TANITA TFW-300 bioimpedance meter, and waist circumference was measured using a fiberglass measuring tape at the midpoint between the anterosuperior iliac spine and the lowest rib, with the patient standing. Blood pressure was determined with a standard, calibrated, aneroid meter as the mean of two measurements three minutes apart. Measurements were taken in sitting position, on the right arm, with the arm slightly bent and placed at heart level, and after a five minute rest. If the first and second measurements differed by more than $10 \mathrm{mmHg}$ a third measurement was taken, and the mean of the three was recorded. During the same appointment, we drew a fasting blood sample and performed a standard two hour oral glucose tolerance test (OGTT) on each participant. Blood lipids and glucose were determined using enzymatic methods and LDL cholesterol (LDLC) was calculated by Friedewald's formula.

\section{Variables}

A standard drink was defined as that containing approximately 12 grams of alcohol: $350 \mathrm{~mL}$ of beer, $120 \mathrm{~mL}$ of wine or $40 \mathrm{~mL}$ of rum (11). Men and women who reported an intake of more than three and four standard drinks at a time respectively were classified as being "at risk of a drinking problem"11. Our indicator of socioeconomic status was the economic stratum; (a classification by the Colombian government based on characteristics of the home and available for all citizens) ${ }^{12}$, as registered in the admission documents, 6 is the highest and 1 the lowest possible value. Occurrence of a cardiovascular event in a relative with at least first degree of consanguinity was considered positive family history of cardiovascular disease, the same applied to family history of HBP, DM2 and obesity. For diagnosis of high or low weight at birth for the gestational age, we employed the Battaglia and Lubchenco criteria ${ }^{13}$.

For those under the age of 18, HBP was defined as blood pressure over the 95th percentile according to reference values for children and adolescents ${ }^{14}$. In this age group, arterial prehypertension was defined as blood pressure (BP) over the 90th percentile or a $\mathrm{BP} \geq 120 / 80 \mathrm{mmHg}$ even if it was below the $90^{\text {th }}$ percentile. For participants 18 years and older, arterial hypertension was defined as a BP $\geq 140 / 90 \mathrm{mmHg}$ and arterial prehypertension as a $\mathrm{BP} \geq 120 / 80 \mathrm{mmHg}^{15}$.

For all ages, a fasting plasma glucose $\geq 100 / \mathrm{mg} / \mathrm{dL}$ was considered impaired fasting glucose (IFG), and a plasma glucose $\geq 140 \mathrm{mg} / \mathrm{dL}$ two hours after oral glucose load in OGTT was considered impaired glucose tolerance. In individuals under 18 years, body mass index (BMI), was interpreted according the International Association for the Study of Obesity (IASO) cutoffs $^{16}$. For those over 18 years, preobesity was defined as a BMI between 25 and $29.9 \mathrm{Kg} / \mathrm{m}^{2}$, and obesity as a BMI $\geq 30 \mathrm{Kg} /$ $\mathrm{m}^{2}$. For participants under 18 , waist circumference (WC) was considered high when above the age and gender-defined 90th percentile ${ }^{17}$. For those 18 years and older, WC was considered high when it was $\geq 80 \mathrm{~cm}$ for women or $\geq 90 \mathrm{~cm}$ for men. For interpretation of plasma lipids age and gender-specific cutoffs by Jolliffe and Janssen ${ }^{18}$ were used.

We diagnosed MS in adolescents following criteria from three different published guidelines: REGODCI ${ }^{19}, I D F^{20}$ and pediatric- $A H A^{21}$. Detailed criteria may be consulted in the respective publications.

\section{Statistical analyses}

Average values of continuous variables were compared between sample subgroups using Student's t test. Proportions were compared between sample subgroups using Pearsons Chi-square test. The relationship between socio-demographic factors, perinatal conditions and $\mathrm{BMI}$ as predictors, and continuous CVRF as dependent variables was estimated and 
adjusted for confounders using multiple linear regression. The relation between socio-demographic factors, perinatal conditions and BMI as predictors, and dichotomous CVRF as dependent variables, was estimated and adjusted for confounders using multiple logistic regression. All statistical analyses were performed with SAS® for Windows, Version 9.1.

\section{Results}

The initial sample consisted of 264 individuals, 15 of whom refused to participate or provide informed consent. From the 249 participants in the definitive sample, 146 (58.6\%) were male and 103 (41.4\%), female. Mean age was 17.6 years for males and 17.5 years for females, and mean BMI was also very similar for both genders: $21.4 \mathrm{Kg} / \mathrm{m}^{2}$ for males and 21.7 $\mathrm{Kg} / \mathrm{m}^{2}$ for females (Table 1 ).

\section{Prevalence of cardiovascular risk factors}

Obesity was the condition most frequently referred to in family history, (40.6\% of participants), followed by HBP (21.7\%) and DM2 (5.6\%) (Table 2). Overweight and obesity were found in $11.2 \%$ and $1.6 \%$, respectively; without significant differences between genders. There was a non-significant difference in the proportion of preobese under 18 and adults (12.3\% vs. $9.9 \%, p=0.54)$, the same trend was found for obesity $(2.17 \%$ vs. $0.9 \% ; p=0.42)$. Prevalence of central obesity for the total sample was $12.0 \%$, four times more frequent in females than males $(21.8 \%$ vs. $5.4 \%, p<0.001)$. We did not find any participant under 18 with a BMI below percentile 5 , however $10.0 \%$ of adults were underweight $\left(\mathrm{BMI}<18.5 \mathrm{Kg} / \mathrm{m}^{2}\right)$.

Arterial prehypertension was present in $14.1 \%$ of participants, four times more in males than females (20.3\% vs. $5.0 \%, p<0.001)$. Arterial hypertension was detected in only $2.0 \%$ of the population, and all affected individuals were males under 18 years.

Prevalence of smoking was $18.9 \%$, higher in males than females (22.3 vs. 13.9, $p=0.09$ ). Although not statistically significant, , prevalence of actual smoking was greater among those 18 and older (23.4\% vs. $15.2 \%, p=0.1)$. Majority of smokers in the study consumed between 1 and 10 cigarettes per week (58.7\%).

None of the study subjects presented diabetes, prevalence of prediabetic states was $4.6 \%$ (impaired fasting glucose [IFG]: $8.4 \%$, impaired glucose tolerance [IGT]: 0.8\%), without significant gender differences. Nevertheless, IFG was more frequent in adults (13.5\%) than in those under $18(4.3 \%)(p=0.009)$.

Mean plasma cholesterol, HDL cholesterol (HDLc) and LDL cholesterol (LDLc) in the study sample were $139.6 \mathrm{mg} /$ $\mathrm{dL}, 51.7 \mathrm{mg} / \mathrm{dL}$ and $69.6 \mathrm{mg} / \mathrm{dL}$, respectively; without differences between genders (Table 1 ). Mean plasma triglycerides were $91.7 \mathrm{mg} / \mathrm{dL}$, significantly higher in males than females $(p=0.02)$. Prevalence of hypertriglyceridemia was $9.2 \%$, and that of low HDLc was $13.3 \%$, much higher in males yet not statistically significant $(p=0.2)$. These two dyslipidemias were much more frequent under 18 than in adults (Table 2). Hypercholesterolemia was found in $6.0 \%$ of the sample, without differences between genders $(p=0.96)$.

Prevalence of alcohol consumption was higher in persons over 18 years $(66.7 \%)$ and men (66.9\%) ( $p=0.01$ for both comparisons). In all socioeconomic strata, more than $45 \%$ of participants reported consuming alcoholic beverages, with a slight trend across strata (from $66 \%$ in stratum 1 to $83 \%$ in stratum 5, there were no participants in stratum 6; p for trend $=0.02$ ). The most frequently consumed beverages were beer $(46.6 \%)$, aguardiente (local beverage distilled from anise) $(7.2 \%)$, wine (3.2\%) and rum (3.2\%). Among alcohol consumers, $31.8 \%$ of men and $19.8 \%$ of women were "at risk of a drinking problem".

\section{Relations among risk factors}

After adjustment by age, gender, smoking, alcohol consumption and gestational age at birth, BMI was positively associated with systolic blood pressure (SBP), diastolic blood pressure (DBP), plasma triglycerides and LDL cholesterol (all $p<0.001$ ) (Table 4). The Odds Ratios [OR] for hypertriglyceridemia, hypercholesterolemia and IFG increased respectively by $24 \%$, $27 \%$ and $15 \%$ per each additional $\mathrm{Kg} / \mathrm{m}^{2}$ of $\mathrm{BMI}(\mathrm{p}=0.004$, $p=0.002$ and $p=0.055$ ); and the OR for high blood pressure (prehypertension or hypertension), increased by $44 \%$ per each additional BMI unit $(p<0.001)$ (Table 5).

In multivariate analysis, males had significantly higher plasma triglycerides $(p=0.01)$, SBP $(p<0.001)$, DBP $(p=0.01)$, WC $(p<0.001)$ and significantly lower percent body fat $(p<0.001)$ than females; females had significantly higher levels of HDLc $(p=0.01)$.

Age was positively associated with fasting glycemia: levels increased by $3.54 \mathrm{mg} / \mathrm{dL}(p<0.001)$ for each additional year. When 2 hours post-load glycemia was categorized in quartiles, each additional year of age increased by $43 \%$ the OR of belonging to the highest quartile $(p=0.02)$.

\section{Perinatal conditions and cardiovascular risk factors}

We found a relation of borderline statistical significance between gestational age at birth and the OR low levels of HDLC: for each additional week of gestation, the OR of presenting low HDLc decreased by $14 \%(p=0.053)$.

A high weight at birth was associated with high blood pressure $(O R=2.5, p=0.02)$. In contrast, this $O R$ decreased by $17 \%$ for each additional week of gestational age at birth $(p=0.03)$.

\section{Comparison between diagnostic criteria of metabolic syndrome}

Prevalence of the MS varied according to the definition used: $2.0 \%$ according to IDF, $2.4 \%$ according to pediatric-AHA, and $9.2 \%$ according to REGODCI (Table 3 ).

\section{Discussion}

Our study shows a high prevalence of several modifiable cardiovascular risk factors among a population of very young college students from a Latin American country. A high body mass index was strongly associated with several risk factors, and a personal history of older gestational age at birth was inversely associated with some of them. We also found huge differences in prevalence of the metabolic syndrome according to the diagnostic criteria employed. 
Despite possible recall bias, our estimates of prevalence of a family history of overweight coincide with prior data from our group (prevalence of adult overweight: $46.9 \%)^{22}$, and with the National Nutritional Survey of Colombia (ENSIN 2005), (Overweight prevalence: $46.1 \%$ ) $^{23}$. Similarly, frequency of a family history of HPB was $21.7 \%$, close to the adult prevalence of this condition in epidemiological studies in Colombian population (Bogotá: 22.2\%, Bucaramanga: 22.9\%)22,24. A prevalence of family history of DM2 of $5.6 \%$, agrees with previous data on prevalence of diabetes in urban centers of Colombia: $7.5 \% 25$.

High blood pressure affected only $2 \%$ of the sample, all males under 18. This is lower than the prevalence described in US Hispanics 15 to 17 years of age $(4.6 \%)^{26}$, probably due to particularities of the Mexican-American population. This highlights that surveys of CVRF in populations of immigrants to industrialized countries may not accurately reflect their prevalence in people of the same ethnicity living in developing countries. On the other hand, the high prevalence of arterial prehypertension $(15.2 \%)$ for those under18 was remarkably higher than in other studies ${ }^{27}$, suggesting an ongoing epidemiologic transition among adolescents in Colombia.

Cigarette smoking generally begins and is established in the early stages of adolescence ${ }^{28}$. Prevalence of smoking in our sample was similar to that in a previous Colombian study of medical students $(19.1 \%)^{29}$, although this might be influenced by the socio-cultural characteristics of the sample, since prevalence of smoking decreases with additional education ${ }^{30}$. Nevertheless prevalence of smoking under 18 in our sample $(15.2 \%)$ was slightly higher than in previous studies with Colombian medical students $(13.9 \%)^{30}$, and Mexican adolescents $(10.1 \%)^{32}$.

Prevalence of overweight among 10-17 years olds in ENSIN 2005 was $10.3 \%{ }^{23}$, a little lower than in our group under 18 . These results become more relevant considering that about $80 \%$ of overweight adolescents will become obese adults ${ }^{33}$.

That we found a non trivial proportion of underweight participants, exposes the double burden of morbidity derived from a poor nutrition from both excess and deficit in our population, the so called nutrition transition ${ }^{34}$. Even though the prevalence of DM2 in people under 20 years of age has been reported as $0.22 \%$ in other countries ${ }^{35}$, we did not find any cases in our sample, probably due to limited power. We did find, however; a surprisingly high prevalence of IFG in adult participants $(13.6 \%)$, actually higher than that reported for North Americans under age $20(7.0 \%)^{36}$, but unlike the North American report, we found no significant difference between genders.

As in prior reports from Colombia and other developing countries $^{31,37}$, the most frequent dyslipidemia was low HDLC $(13.3 \%)$, followed by hypertriglyceridemia $(9.2 \%)$ and then hypercholesterolemia (6.0\%). Given that 40 to $55 \%$ of children and adolescents with high levels of TC and LDLc will track these high levels up to 15 years later $^{38}$, the possibility that these dyslipidemic young individuals will become adults at high risk of cardiovascular disease justifies early intervention strategies.

Higher BMIs were associated to higher body fat, WC, SBP, DBP, fasting glucose, triglycerides and LDLC. This agrees with prior studies where adolescents with high BMI not only present higher lipid and blood pressure level $\mathrm{s}^{39,40}$, but also higher fasting insulinemia ${ }^{41}$ and insulin resistance ${ }^{42}$. To contextualize our findings regarding $W C$ and abdominal obesity is difficult because: I) Although WC is a good predictor of CVRF in children ${ }^{43}$, the same is not true for young men ${ }^{37}$, for whom the BMI seems to have a better predictive value to identify CVRF, II) The WC value does not affect therapeutic management when BMI and other CVRF are determined simultaneously ${ }^{44}$ and III) Despite the existence of WC reference values in Mexican-American, African -American, Brazilian, Spanish, Australian, British and Canadian teenagers ${ }^{44}$ there is no agreement about a cutoff point for WC in children and adolescents that can be associated with morbidity later in life.

As expected, females had higher levels of body fat and HDLC, and males had higher levels of blood pressure, triglycerides and WC, though women had a greater chance of presenting abdominal obesity because of the different cutoffs.

With respect to the other diagnostic proposals, use of REGODCI criteria led to a greater estimate of MS prevalence. This definition suggests laboratory determinations for a second step, after first confirming suspicion of MS; by clinical criteria making it a desirable choice for resource-strained environments such as those in developing countries.

In concordance with prior reports of association between premature birth and insulin resistance ${ }^{45}$, and other CVRF such as dyslipidemia and $\mathrm{HBP}^{46}$, we found a negative association between gestational age at birth and HBP or low HDLc. This highlights the great impact that conditions early in life may have on subsequent health, and deserves further exploration in future studies.

A limitation of our study is that its results cannot be extrapolated to the general young population in Bogotá, due to the sociocultural and educational level of participants. Notwithstanding, our results provide a useful initial approximation to study CVRF in young people from Bogotá and other urban centers in Latin America. Likewise, since we did not quantify physical activity or caloric and nutrient intake, study results may be subject to residual confounding.

Another relevant limitation of our study is that we did not collect Tanner stages or other measures of sexual maturation in participants, and sexual maturation may be correlated to lipid levels. However, hormonal changes associated with sexual maturation that might impact plasma lipids tend to occur during puberty, rather than in the age group studied (15-20 years, mean age 17.6), so it is possible that the impact of sexual maturation on the observed results may be limited.

\section{Conclusion}

In conclusion, the most prevalent CVRF was smoking. Arterial prehypertension was also very frequent, closely followed by low HDLc. Approximately one of each ten young individuals in the sample showed prediabetes or overweight. These CVRF are intimately related with lifestyle. These results should foster the development of promotion and prevention programs geared toward this age group in educational and health institutions.

Financial Support: This work was partially sponsored by the División de Salud Estudiantil from the National University of Colombia, Bogotá

Conflict of Interest: None 


\section{Resumo}

\section{Fatores de Risco cardiovascular e síndrome metabólica em uma população de estudantes jovens da Universidade Nacional DE ColômBia}

OBjetivo. Estimar a prevalência e distribuição de fatores de risco cardiovasculares e da síndrome $X$ metabólica (SM) em indivíduos jovens admitidos na Universidade Nacional da Colômbia, em Bogotá.

Métodos. Foi realizado um estudo analítico transversal em uma amostra de 249 indivíduos de ambos os sexos, com idades entre 15 e 20 anos. Um questionário foi administrado pessoalmente para recolher dados demográficos e socioeconômicos, presença ou ausência de tabagismo, características perinatais e sobre saúde da mulher. Medidas antropométricas e de pressão arterial foram realizadas, e uma amostra de sangue em jejum foi coletada. A prevalência da SM foi determinada e comparada utilizando-se os critérios de diferentes instituções especializadas.

RESULTADOS. Encontramos uma alta prevalência de tabagismo (18,9\%), pré-hipertensão arterial (14,1\%) e sobrepeso (11,2\%); 9,2\% dos participantes tinham pré-diabetes, e a mais frequente dislipidemia foi baixo HDL-colesterol (13,3\%). Um total de 66,6\% dos participantes declarou consumir bebidas alcoólicas. 0 índice de massa corporal foi positivamente associado a aumento na pressão arterial, colesterol LDL e triglicérides plasmáticos. A idade gestacional ao nascimento foi inversamente associada a baixo HDL colesterol e à pressão arterial elevada. A prevalência de SM variou acentuadamente, de acordo com a definição empregada: 9,2\% segundo REGODCI (Grupo de Pesquisa em Diabetes e Doenças Crônicas), 2\% segundo IDF (International Diabetes Federation), e 2,4\% segundo AHA (American Heart Association).

Conclusão. A prevalência encontrada de fatores de risco cardiovasculares justifica o incentivo a mudanças de estilo de vida neste grupo etário na Colômbia. Uma maior padronização dos critérios definidores de SM em indivíduos jovens é necessária. [Rev Assoc Med Bras 2010; 56(3): 293-8]

Unitermos: Fatores de risco. Adolescente. Síndrome X metabólica. Obesidade. Consumo de bebidas alcoólicas.

\section{REFERENCES}

1. Jessup A, Harrell J. The metabolic syndrome: look for it in children and adolescents, too! Clin Diabetes. 2005;23:26-32.

2. Mendivil CO, Sierra ID. Advances in obesity. Rev Fac Med Univ Nac Colomb. 2004;52:270-286.

3. Guillaume M, Lapidus L, Lambert A, Bjorntorp P. Socioeconomic and psychosocial conditions of parents and cardiovascular risk factors in their children: The Belgian Luxembourg Child Study III. Acta Paediatr. 1999;88:866-73.

4. Berenson GS, Wattigney WA, Tracy RE, Newman III WP, Srinivasan SR, Webber LS. et al. Atherosclerosis of the aorta and coronary arteries and cardiovascular risk factors in persons aged 6 to 30 years and studied a necropsy (The Bogalusa Heart Study). Am J Cardiol. 1992;70:851-8.

5. Berenson GS, Srinivasan SR, Bao W, Newman III WP, Tracy RE, Wattigney WA Association between multiple cardiovascular risk factors and atherosclerosis in children and young adults. N Engl J Med. 1998; 338:1650-6.

6. National Department of Statistics of Colombia (DANE). 1998 Death Registry. Referenced in: Ministerio Nacional de Salud de Colombia. Situación de Salud en Colombia, Indicadores Básicos 2001. Bogotá: Ministerio Nacional de Salud; 2002.

7. Irving RJ, Belton WR, Elton RA, Walter BR. Adult cardiovascular risk factors in premature babies. Lancet. 2000;355:2135-6.
8. Office of Curricular Programs of the National University of Colombia: Problemas curriculares y pedagógicos del pregrado en la Universidad Nacional de Colombia. [(cited 2009 apr 16]. Available from: http:// www.unal.edu.co/noticias/claustros_y_colegiaturas/documentos/ problemas_curriculares_pregrado_un.doc)

9. Rosner B. Fundamentals of biostatistics. 5th ed. Pacific Grove: Duxbury Press; 1998.

10. Ford ES, Giles WH, Dietz WH. Prevalence of the metabolic syndrome among US adults: findings from the Third National Health and Nutrition Survey. JAMA. 2002; 287:356-9.

11. Enoch MA, Goldman D. Problem drinking and alcoholism: diagnosis and treatment. Am Fam Physician. 2002;65:441-8.

12. Congreso de Colombia. Ley 142 de 1994: "Por la cual se establece el régimen de los servicios públicos domiciliarios y se dictan otras disposiciones.", Articulo 102. Available from: http://www.sanandres.gov.co/documentos/ normatividad/Secretaria de Hacienda/ley 142 de 1994.pdf.

13. Battaglia FC, Lubchenco LO. A practical classification of newborn infants by weight and gestational age. J Pediatr 1967;71:159-163

14. National High Blood Pressure Education Program Working Group on High Blood Pressure in Children and Adolescents. The fourth report on the diagnosis, education and treatment of high blood pressure in children and adolescents. Pediatrics 2004;114: 555-576.

15. Chobanian AV, Bakris GL, Black HR, Cushman WC, Green LA, Izzo JL Jr. et al. The Seventh Report of the Joint National Committee on Prevention, Detection, Evaluation, and Treatment of High Blood Pressure: the JNC 7 report. JAMA 2003,289:2560-2572.

16. Lobstein T, Baur L, Uauy R. for the IASO International Obesity Task Force. Obesity in children and young people: a crisis in public health. Obes Rev 2004;5(suppl. 1):4-85.

17. Hirscheler V, Aranda C, Calcagno M, Maccalini G, Jadzinsky M. Can waist circumference identify children with the metabolic syndrome? Arch Pediatr Adolesc Med 2005;159:740-744.

18. Jolliffe CJ, Janssen I. Distribution of lipoproteins by age and gender in adolescents. Circulation 2006;114;1056-1062.

19. Rodríguez M, Salazar B, Violante R, Guerrero F. Metabolic syndrome among children and adolescents aged 10-18 years. Diabetes Care 2004:27:2516-2517.

20. Zimmet P, Alberti G, Kaufman F, Tajima N, Silink M, Arslanian S et al, on behalf of the International Diabetes Federation Task Force on Epidemiology and Prevention of Diabetes. The metabolic syndrome in children and adolescents. Lancet 2007;369: 2059-2061.

21. Goodman E, Daniels SR, Meigs JB, Dolan LM. Instability in the diagnosis of metabolic syndrome in adolescents. Circulation 2007;115:2316-2322.

22. Mendivil CO, Sierra ID, Perez CE. Global cardiovascular risk assessment and prevalence of dyslipidemias according to NCEP-ATPIII criteria in an adult population from Bogotá, Colombia. Clin Invest Arterioscl 2004;16:98-107. Spanish.

23. National Survey of Nutritional status in Colombia (ENSIN 2005). (Accessed April 16, 2009, at: http://scp.com.co/Archivosscp/ensin_ICBF_2005.pdf).

24. Bautista LE, Vera-Cala LM, Villamil L, Silva SM, Peña IM, Luna LV. Risk factors associated with the prevalence of arterial hypertension in adults in Bucaramanga, Colombia. Salud Publica Mex 2002;44:399-405. Spanish.

25. Aschner P, King H, Triana de Torrado M, Rodriguez BM. Glucose intolerance in Colombia: A population-based survey in an urban community. Diabetes Care 1993;16:90-93.

26. Din-Dzietham R, Liu Y, Bielo MV, Shamsa F. High blood pressure trends in children and adolescents in national surveys, 1963 to 2002. Circulation 2007; 116:1488-1496.

27. Hansen ML, Gunn PW, Kaelber DC. Underdiagnosis of hypertension in children and adolescents. JAMA 2007;298:874-879.

28. Jackson C, Dickinson D.Cigarette consumption during childhood and persistence of smoking through adolescence. Arch Pediatr Adolesc Med 2004;158:1050-1056.

29. Roselli D, Rey O, Calderón C, Rodríguez MN. Smoking in Colombian Medical schools: the hidden curriculum. Prev Med 2001;33:170-174.

30. Pekkanen J, Uutela A, Valkonen T, Vartianen E, Toumiletho J, Puska P. Coronary risk factors levels: differences among educational groups in 1972-87 in Eastern Finland. J Epidemiol Community Health 1995;144-149.

31. Uscátegui Peñuela RM, Alvarez Uribe MC, Laguado Salinas I, Soler Terranova W, Martínez Maluendas L, Arias Arteaga R et al. Cardiovascular risk factors in children and teenagers aged 6-18 years old from Medellín (Colombia). An Pediatr 2003:58: 411-417. Spanish.

32. Kuri-Morales PA, Gónzalez-Roldán JF, Hoy MJ, Cortés-Ramírez M. Epidemiology of smoking in Mexico. Salud Publica Mex 2006;48(suppl.1):S91-S98. Spanish.

33. Whitaker RC, Wright JA, Pepe MS, Seidel KD, Dietz WH. Predicting obesity in young adulthood from childhood and parental obesity. N Engl J Med 1997;337:869-873

34. Caballero B. A nutrition paradox: Underweight and obesity in developing countries. New Engl J Med 2005;352:1514-1516. 
35. Centers for Disease Control and Prevention: National Diabetes Factsheet (Accessed April 16, 2009 at: www.cdc.gov/diabetes/pubs/pdf/ndfs 2003. pdf).

36. Williams DE, Cadwell BL, Cheng YL, Cowie CC, Gregg EW, Geiss LS et al. Prevalence of impaired fasting glucose and its relationship with cardiovascular disease risk factors in US adolescents, 1999-2000. Pediatrics 2005;116:1122-1126

37. Kelishadi R, Gheiratmand R, Ardalan G, Adelli K, Gouya MM, Razaghi EM et al. Association of anthropometric indices with cardiovascular disease risk factors among children and adolescents. CASPIAN study. Int J Cardiol 2007; 117:340-348.

38. Haney EM, Huffman LH, Bougatsos C, Freeman M, Steiner RD, Nelson HD. Screening and treatment for lipids disorders in children and adolescents: systematic review for the US Preventive Services Task Force. Pediatrics 2007; 120:e189-e214.

39. Lauer RM, Lee J, Clarke WR. Factors affecting the relationship between childhood and adult cholesterol levels. The Muscatine Study. Pediatrics 1988;82:309-318.

40. Srinivasan SR, Bao W, Wattigney WA, Berenson GS. Adolescent overweight is associated with adult overweight and related multiple cardiovascular risk factors: the Bogalusa Heart study. Metabolism 1996;45:235-240.

41. Sinaiko AR, Steinberger J, Moran A, Prineas RJ, Vessby B, Basu S, et al. Relation of body mass index and insulin resistance to cardiovascular risk factors, inflammatory factors and oxidative stress during adolescence. Circulation 2005;111:1985-1991.

42. Weiss R, Dziura J, Burget TS, Tamborlane WV, Taksali SE, Yeckel CW et al. Obesity and the metabolic syndrome in children and adolescents. N Engl J Med 2004;350:2362-2374.
43. Savva SC, Tornaritis M, Savva ME, Kourides Y, Pánagi A, Silokiotou N, et al. Waist circumference and waist-to-height ratio are better predictors of cardiovascular disease risk factors in children than body mass index. Int J Obes 2000;24:1453-1458.

44. Klein S, Allison DB, Heysfield SB, Kelley DE, Leibel RL, Nomas C et al. Waist circumference and cardiometabolic risk: a consensus statement from Shaping America's Health: Association for Weight Management and Obesity Prevention, NAASO, The Obesity Society; the American Society for Nutrition, and the American Diabetes Association. Am J Clin Nutr 2007;85:1197-1202.

45. Hofman PL, Regan F, Jackson WE, Jefferies C, Knight DB, Robinson EM et al. Premature birth and later insulin resistance. N Engl J Med 2004;351:2179-2186.

46. Rotteveel J, van Weisssenbruch MM, Twisk JWR, Delemarre-Van de Waal. Abnormal lipid profile and hyperinsulinemia after a mixed meal: additional cardiovascular risk factors in young adults born preterm. Diabetologia 51:1269-1275.

Artigo recebido: 24/7/09

Aceito para publicação: 10/3/10 